\title{
The importance of Böhler's angle in calcaneus geometry: A finite element model study
}

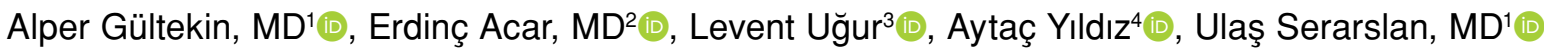 \\ ${ }^{1}$ Department of Orthopedics and Traumatology, Kocaeli Derince Training and Research Hospital, Kocaeli, Turkey \\ ${ }^{2}$ Department of Orthopedics and Traumatology, Division of Hand and Upper Extremity Surgery, Ankara City Hospital, Ankara, Turkey \\ ${ }^{3}$ Department of Mechanical Engineering, Amasya University, Faculty of Technology, Amasya, Turkey \\ ${ }^{4}$ Department of Industrial Engineering, Bursa Technical University, Bursa, Turkey
}

Calcaneus fractures are the most common fractures of the hindfoot, accounting for 1 to $2 \%$ of all fractures of the human skeleton. ${ }^{[1,2]}$ The majority of injuries involve the subtalar joint (about 75\%) and the calcaneocuboid joint (about 68\%). ${ }^{[2-4]}$ The subtalar joint, the determinative joint of the hindfoot, is often disrupted by fractures of the calcaneus. The main goal of treatment for calcaneal fractures must be restoration of the joint and, particularly, calcaneal height, length, and heel width restitution..$^{[5,6]}$

Several studies support the notion that a congruous anatomic reconstruction of the joint surface is critical for optimal clinical outcomes after operative treatment. ${ }^{[7,8]}$ Most authors use the Böhler's angle. The Böhler's historical tuber-joint angle of the calcaneus has been used since 1931. ${ }^{[9]}$ The intersection of two lines forms the Böhler's angle: a line is drawn between the posterior superior aspect of the calcaneus and

Received: January 18, 2021

Accepted: March 14, 2021

Published online: June 11, 2021

Correspondence: Erdinç Acar, MD. Ankara Sehir Hastanesi Ortopedi ve Travmatoloji Kliniği, El ve Üst Ekstremite Cerrahis Bölümü, 06800 Çankaya, Ankara, Türkiye.

E-mail: erdal240@gmail.com

\section{Doi: $10.52312 / j d r s .2021 .81251$}

Citation: Gültekin A, Acar E, Uğur L, Yıldız A, Serarslan U. The importance of Böhler's angle in calcaneus geometry: A finite element model study. Jt Dis Relat Surg 2021;32(2):420-427.

(C2021 All right reserved by the Turkish Joint Diseases Foundation

This is an open access article under the terms of the Creative Commons Attribution-NonCommercial License, which permits use, distribution and reproduction in any medium, provided the original work is properly cited and is not used for commercial purposes (http://creativecommons.org/licenses/by-nc/4.0/).

\section{ABSTRACT}

Objectives: Calcaneal fractures are the most common tarsal fractures following a foot-ankle trauma. The Böhler's angle is an important measurable angle before, during, and after surgery. In this study, we aimed to investigate correlation between Böhler's angle, calcaneal strength, and subtalar joint stress using a finite element analysis (FEA)

Patients and methods: Between January 2016 and December 2016, computed tomography (CT) scans were used with MIMICS ${ }^{\circledR}$ software for FEA. The ankle and foot of a 23-year-old male person with a height of $180 \mathrm{~cm}$ and weighing $80 \mathrm{~kg}$ was modeled as reference. Raw coronal CT images were obtained in Digital Imaging and Communications in Medicine format with the resolution of $512 \times 512$ pixels and $0.3-\mathrm{mm}$ slice intervals in $135 \mathrm{kV}$. The structures including tibia, fibula and 26 other bones (talus, calcaneus, cuboid, navicular, three cuneiforms, five metatarsals, and 14 components of phalanges), cartilage and ligamentous tissues were modeled to form ankle joint. After determining Böhler's angle as 35 degrees for the reference model, a fracture line was created on calcaneus. Calcaneus was remodeled with the Böhler's angle of 45, 40, 30, 25, 20, 10, and 0 degrees respectively. All models were transferred to ANSYS software for FEA and the loads on the lower extremities with normal posture were applied on models.

Results: Analysis of all models based in the reference model revealed that maximum tension values on calcaneus increased, while the Böhler's angle decreased, indicating a statistically significant difference. The decreased Böhler's angle indicated statistically significantly higher maximum tension values $(p=0.04)$. Action force in subtalar joint was evaluated by comparing with the forces in reference model. The increased Böhler's angle was found to be associated with statistically significantly decreased amount of load on subtalar joint. The decreased Böhler's angle was related to the statistically significantly increased amount of load on subtalar joint.

Conclusion: Our study results suggest that decreased Böhler's angle increases the possibility of subtalar arthrosis, although overcorrection of the Böhler's angle seems not to increase the risk of subtalar arthrosis.

Keywords: Biomechanics, Böhler, calcaneus, finite element analysis, fracture, subtalar arthrosis. 
the highest point of the posterior subtalar articular surface; a second line, which intersects the first, is drawn from the highest point of the anterior process to the posterior margin of the subtalar surface (Figure 1). The angle ranges between 20 and 40 degrees; a decrease in this angle indicates collapse of the posterior facet of the calcaneus. There are many studies examining the correlation between the Böhler's angle and the functional outcome of displaced intra-articular calcaneal fractures. ${ }^{[10,11]}$ In calcaneus fractures, the Böhler's angle is one of the most objective indicators of intraoperative (after reduction) and fracture follow-up. However, it is not the one. ${ }^{[12]}$ In the literature, decreased Böhler's angle has been shown to be an important parameter in the diagnosis of fractures and increased stress load. ${ }^{[13]}$

Novel therapeutic modalities can be developed with a better understanding the effects of intra-articular calcaneal fractures to the joint mechanics and relationship between osteoarthritis and altered biomechanics. In parallel with the recent advances in engineering stress analysis, techniques for predicting the behavior of structures with complex geometry and material properties have been developed, and the most appropriate is the finite element analysis (FEA). ${ }^{[14]}$ Finite element modeling is a well-established method to the joint contact stresses. ${ }^{[15,16]}$

In the present study, we aimed to investigate the relationship between the Böhler's angle and the stresses on the calcaneus and the subtalar joint compared to the healthy model. In our FEA, we examined any correlation between the Böhler's angle, calcaneal strength, and subtalar joint stress.

\section{PATIENTS AND METHODS}

A three-dimensional (3D) model of the human foot and ankle was obtained to evaluate the effect of different Böhler's angles on the subtalar joint due to the loads created on the ankle between January 2016 and December 2016. In this study, a left foot and ankle joint of a 23-year-old male person with a normal anatomy with a body weight of $80 \mathrm{~kg}$ and height of $180 \mathrm{~cm}$ were modeled as a reference model through Materialise's Interactive Medical Image Control System (MIMICS $^{\circledR}$ version 10.01;Materialise NV, Leuven, Belgium) program for FEA, of which computed tomography (CT) images are shown in Figure 2. The Toshiba Aquilion CT device (Canon Medical Aquilion series) was used for CT imaging of the patient at Kocaeli Derince Training and Research Hospital. Coronal CT images were obtained in Digital Imaging and Communications in Medicine (DICOM) format by performing scanning at $135 \mathrm{kV}$ with a cross-sectional thickness of $0.3 \mathrm{~mm}$ and a resolution of $512 \times 512$ pixels. The study was conducted in accordance with the principles of the Declaration of Helsinki.

The geometries obtained from the MIMICS ${ }^{\circledast}$ software were converted to stereolithography format, and a 3D ankle model including the tibia, fibula, and 26 bones forming the ankle joint (talus, calcaneus, cuboid, navicular, three cuneiforms, five metatarsals and 14 components of the phalanges) was obtained through the GEOMAGIC ${ }^{\circledR}$ (3D Systems Inc., NC, USA), which was the reverse engineering software (Figure 3). The obtained models were sent to the SolidWorks ${ }^{\circledR} 2015$ software (SolidWorks Corp., MA, USA) and the cartilage tissues forming the ankle were modeled.

We created an ankle model with a Böhler's angle of 35 degrees and, then, created a fracture. Following this, we reduced the fracture to a different Böhler's angle and measured the acting forces to the subtalar joint. We tested different post-reduction Böhler's angles. The Böhler's angle was remodeled to be $40^{\circ}$, $45^{\circ}, 30^{\circ}, 25^{\circ}, 20^{\circ}, 10^{\circ}$, and $0^{\circ}$, respectively (Figure 3 ).

\section{Mesh and material properties}

A tetrahedral mesh network structure was created on the foot model through ANSYS $^{\circledR}$ Workbench version 17.0 software (ANSYS Inc., PA, USA) (Figure 4). The network structure size was determined as $2 \mathrm{~mm}$ in bone structures. Our models consist of about 153,910 nodes and 85,608 elements. Solid 185 and solid 285 were used as the element types. All analyses were made non-linearly.

In accordance with the literature, material properties for bone and soft tissue forming the foot and ankle were selected as isotropic materials (Table I). ${ }^{[17-21]}$

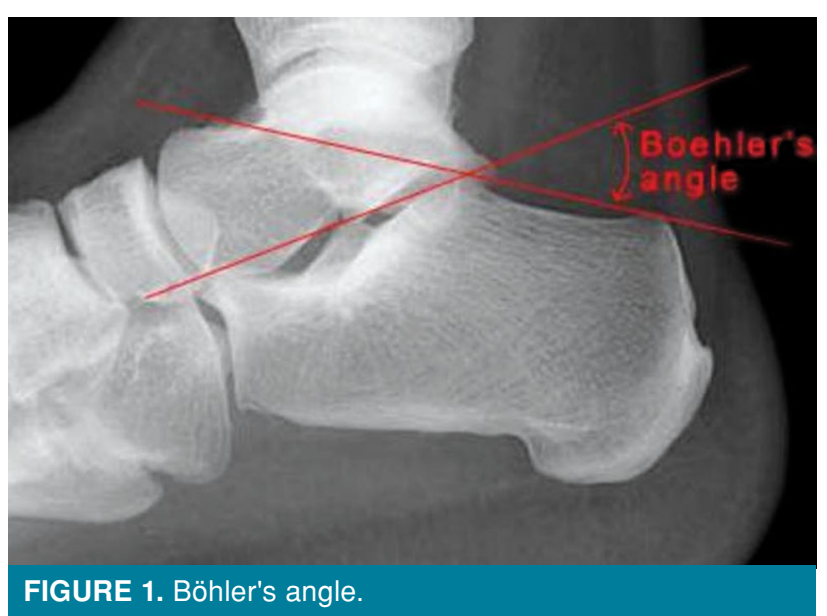




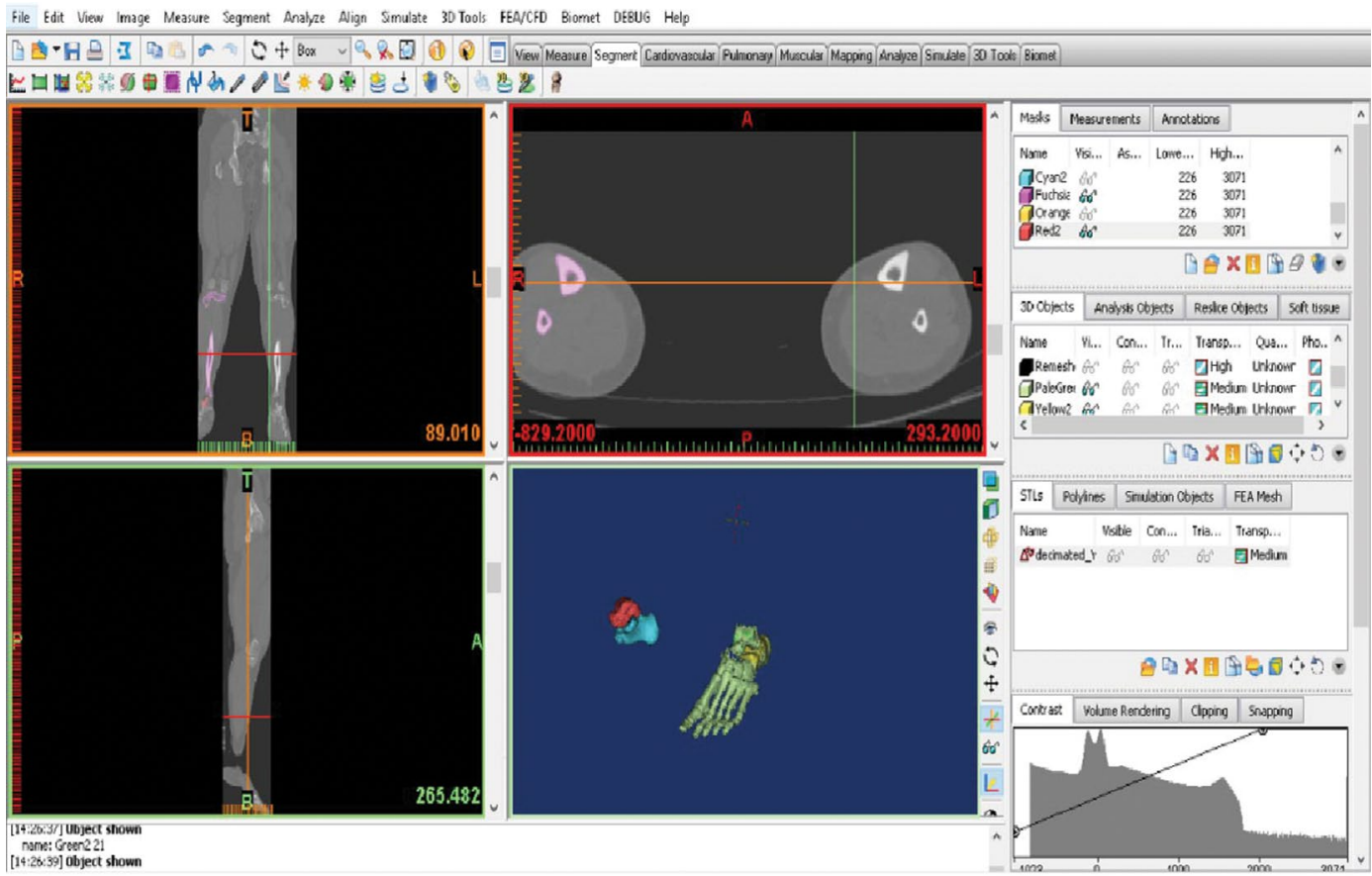

FIGURE 2. Model creation on computed tomography images.

\section{Boundary and loading conditions}

Bonded contact between tibia-talus and cartilages, frictionless contact between cartilages, and bonded contact between bone structures were introduced by following the introduction of material properties. We only evaluated static axial load. The surfaces of the other foot bones, which were in contact with the calcaneus and ground, were fixed and an axial load of $500 \mathrm{~N}$ was applied over the tibia (Figure 5). The measurement was made from the subtalar joint at the time of loading.

The same boundary conditions were used in all models. Finally, a convergence analysis was conducted (Figure 6). The force convergence was commonly used in non-linear analyses.
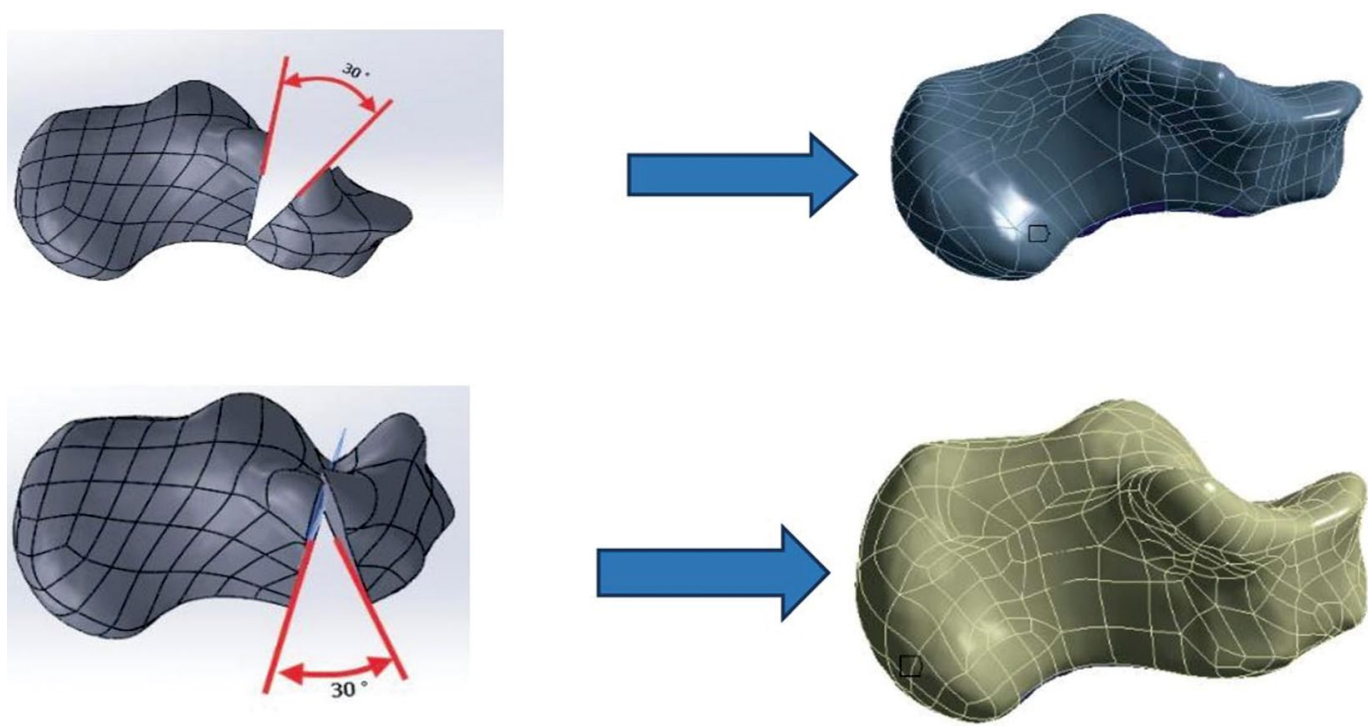

FIGURE 3. Determination of the Böhler's angle. 


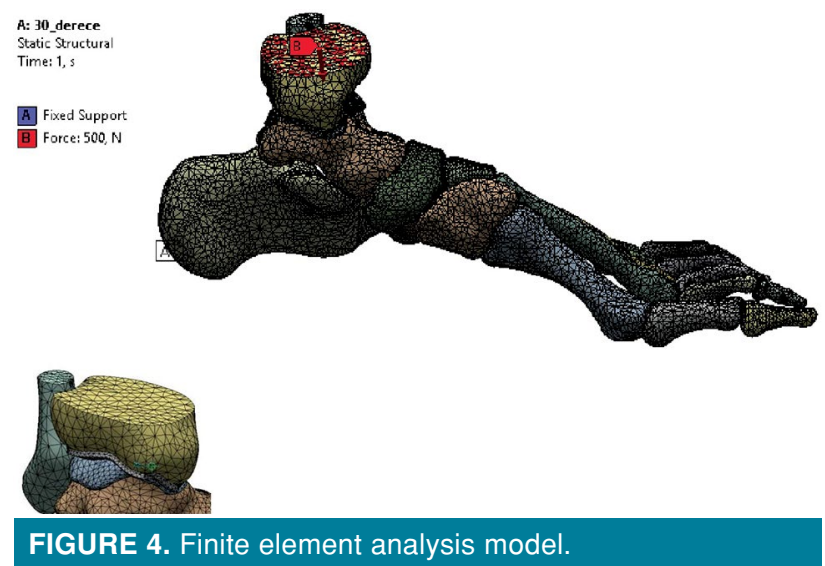

\section{Statistical analysis}

Statistical analysis was performed using the SPSS version 16.0 software (SPSS Inc., Chicago, IL, USA). One-way analysis of variance (ANOVA) and Levene's test were used for to examine significant differences between the Böhler's angle and subtalar joint pressure. Pearson's correlation analysis was performed to identify the direction of change of the pressure on the subtalar joints through the change in Böhler's angle. A $p$ value of $<0.05$ was considered statistically significant.

\section{RESULTS}

A Maximum equivalent stress occurred on the calcaneus, as obtained through non-linear stress analyses, and the reaction force outcomes on the subtalar joints are shown in Table II.

According to the reference model, it was found that the maximum stress on the calcaneus increased, as the Böhler's angle decreased $(<350)$, and there was a statistically significant difference (Figure 7). Stress increased, as the Böhler's angle increased

\begin{tabular}{|c|c|c|}
\hline \multicolumn{3}{|c|}{$\begin{array}{l}\text { TABLE I } \\
\text { Material properties of bones andbone structures }{ }^{[17-21]}\end{array}$} \\
\hline & Young modulus & Poisson ratio \\
\hline & (E) (MPa) & (y) \\
\hline Femur & 17.000 & 0.3 \\
\hline Tibia & 14.000 & 0.3 \\
\hline Fibula & 7000 & 0.3 \\
\hline $\begin{array}{l}\text { Calcaneus and other } \\
\text { foot bones }\end{array}$ & 5000 & 0.3 \\
\hline Cartilage & 10 & 0.46 \\
\hline MPa: Megapascal. & & \\
\hline
\end{tabular}

(>350); however, the obtained stress values were found to be closer to the reference model, and a statistically significant difference was observed in terms of the obtained values. The stress distribution on the calcaneus in the model with the Böhler's angle of $45^{\circ}$ is given in Figure 8 .

Additionally, the reaction force occurred on subtalar joint was compared with the reference model, and reaction forces were determined in this way. Direction of the reaction force occurred on the subtalar joint is shown in Figure 9.

The results of the ANOVA one-way analysis of variance (ANOVA) analysis are shown in Table III. The variance of the groups was homogeneous $(p=0.187)$. Accordingly, homogeneity test of the variances of the groups was performed. There was also a significant difference between the subtalar joint pressure and Böhler's angle, indicating that the pressure on the joints would change as the Böhler's angle changed $(\mathrm{p}=0.043)$ (Table IV).

Correlation analysis results are given in Table V. Accordingly, a strong negative $(\mathrm{r}=-0.832)$ relationship was observed between the Böhler's angle and the pressure on the subtalar joint, indicating that the pressure on subtalar joint decreased, as the Böhler's angle increased, and vice versa.
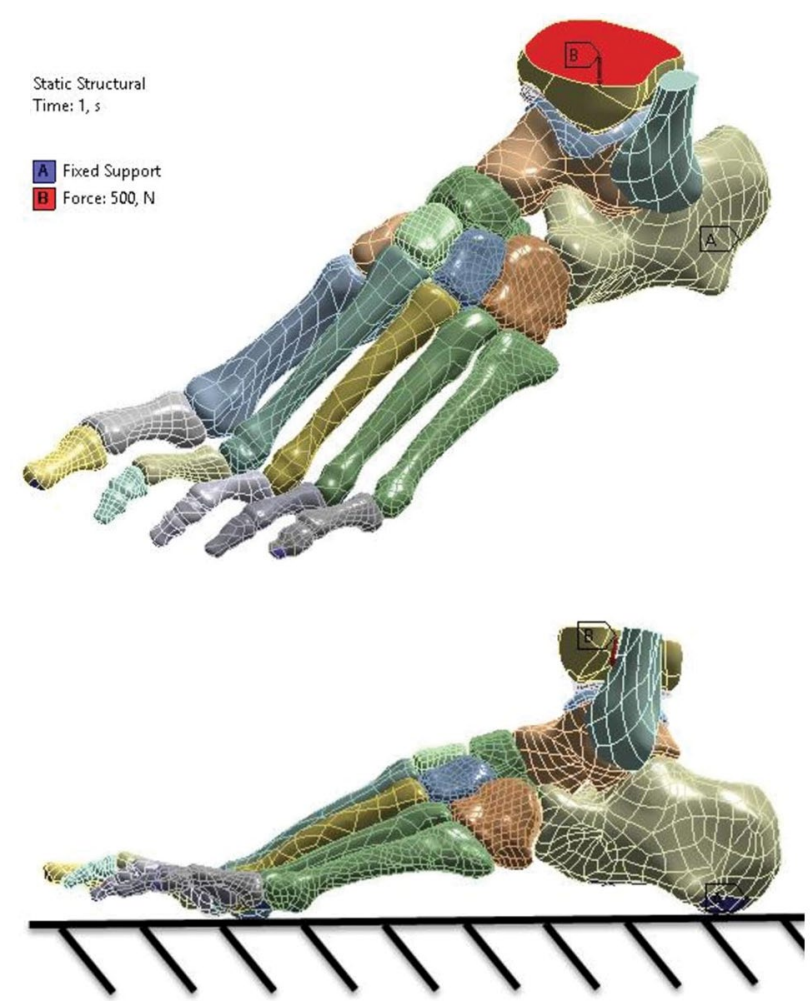

FIGURE 5. Finite element analysis loading conditions. 

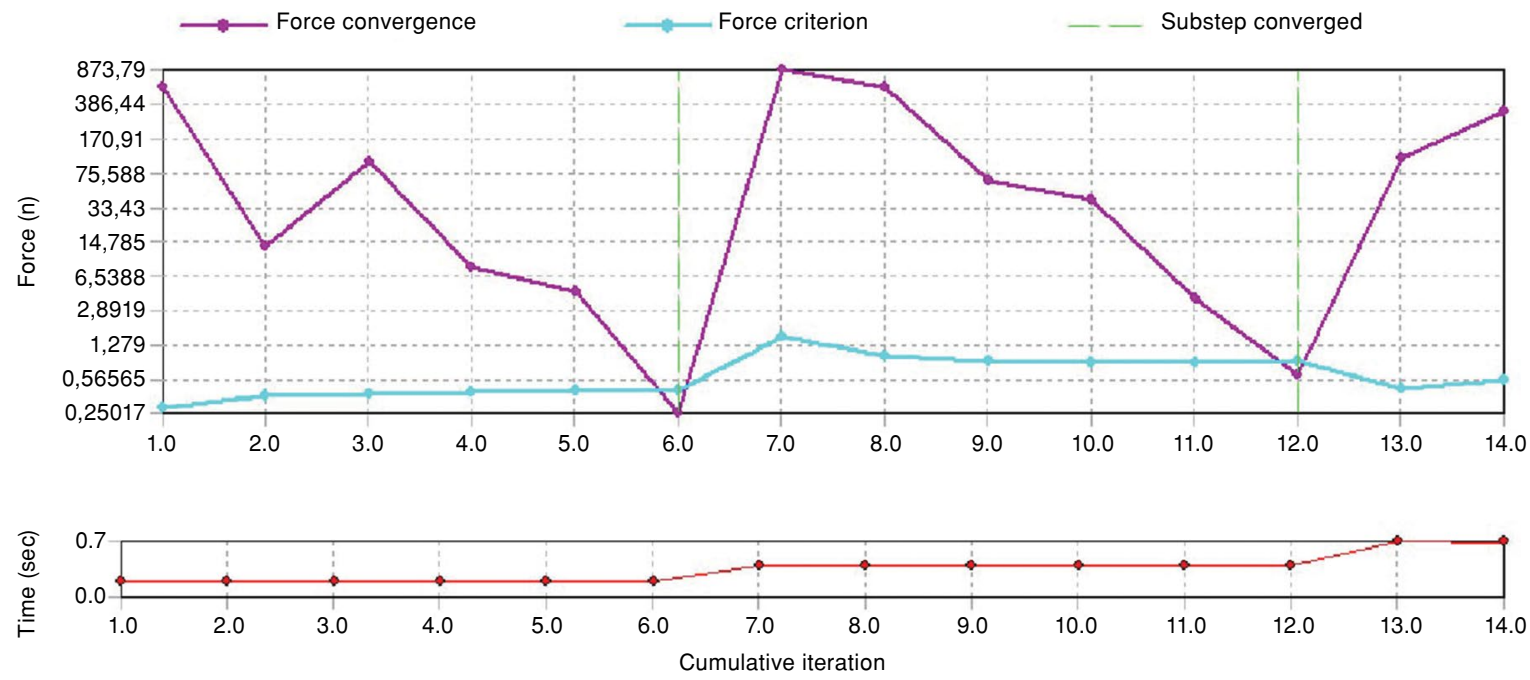

FIGURE 6. Convergence analysis.

\begin{tabular}{|c|c|c|c|c|c|c|}
\hline \multirow[b]{3}{*}{ Models } & \multicolumn{3}{|c|}{$\begin{array}{c}\text { TABLE II } \\
\text { Analysis results }\end{array}$} & & & \\
\hline & \multicolumn{6}{|c|}{ Force reaction } \\
\hline & Calcaneal maximum stress & $\chi$ & $y$ & $z$ & Total & $p$ \\
\hline Böhler's angle $\left(0^{\circ}\right)$ & 45.85 & 10.87 & -228.75 & 499.92 & 560.85 & 0.04 \\
\hline Böhler's angle $\left(10^{\circ}\right)$ & 41.45 & 8.75 & -225.33 & 499.92 & 553.15 & 0.042 \\
\hline Böhler's angle $\left(20^{\circ}\right)$ & 38.75 & 6.47 & -220.15 & 499.92 & 550.24 & 0.045 \\
\hline Böhler's angle $\left(25^{\circ}\right)$ & 35.51 & 5.3023 & -210.01 & 499.92 & 542.27 & 0.048 \\
\hline Böhler's angle $\left(30^{\circ}\right)$ & 32.414 & 19.9 & -279.97 & 499.92 & 573.33 & 0.049 \\
\hline Normal model $\left(35^{\circ}\right)$ & 13.736 & -4.2379 & -187.11 & 499.92 & 533.81 & $>0.05$ \\
\hline Böhler's angle $\left(40^{\circ}\right)$ & 20.838 & 17.572 & -158.47 & 499.92 & 524.73 & $>0.05$ \\
\hline Böhler'sangle $\left(45^{\circ}\right)$ & 25.7 & 4.2649 & -170.25 & 499.92 & 528.14 & $>0.05$ \\
\hline
\end{tabular}

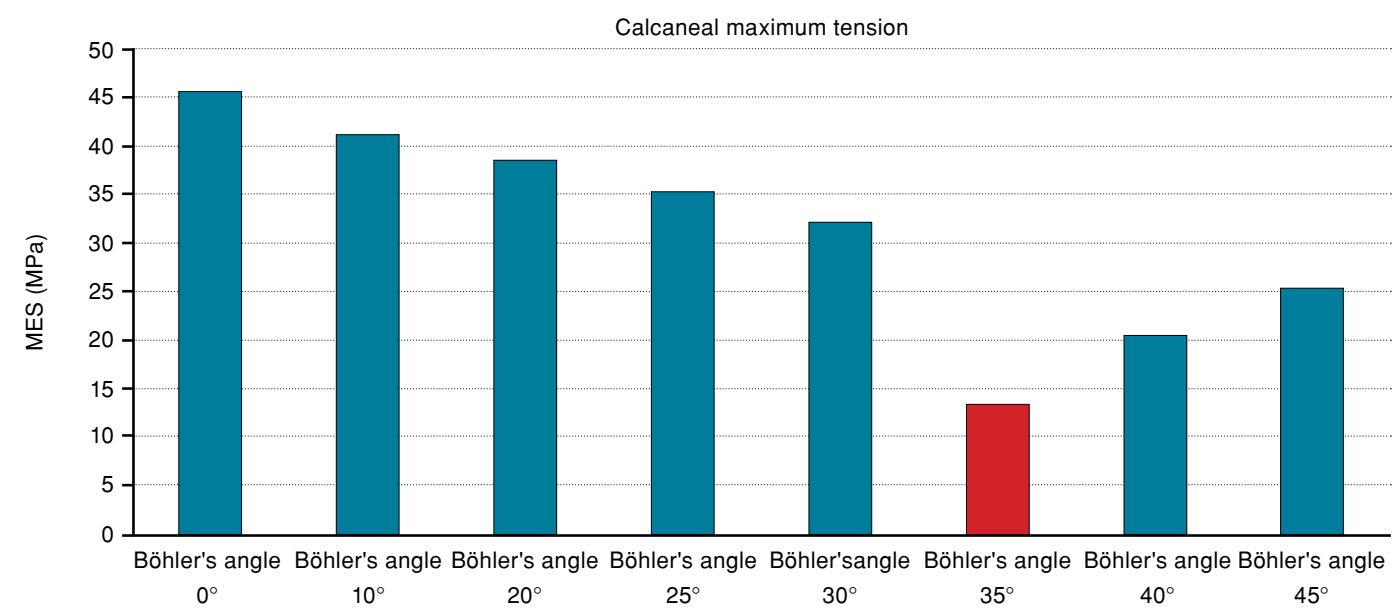

FIGURE 7. Maximum element size (MES) occurred on calcaneus. 


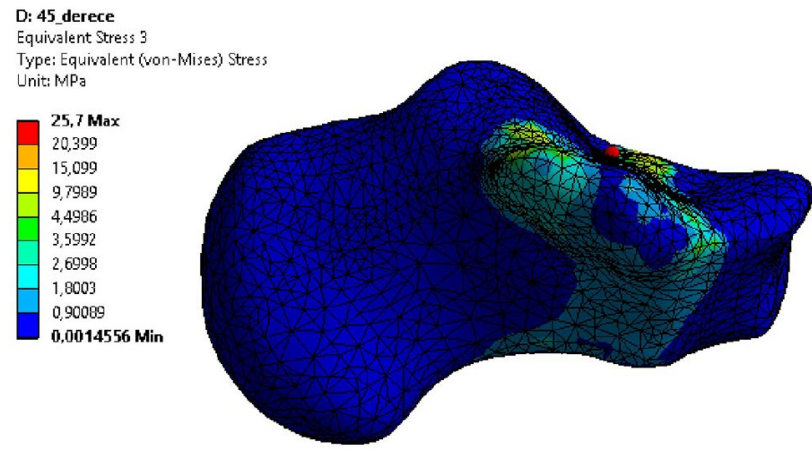

FIGURE 8. Stress distribution on the calcaneus in the model with the Böhler's angle of $45^{\circ}$.

\section{TABLE III}

Test for homogeneity of variances

Subtalar joint pressure

Levene's test statistic df1 df2 Significant

2,341

$1 \quad 5 \quad 0.187$

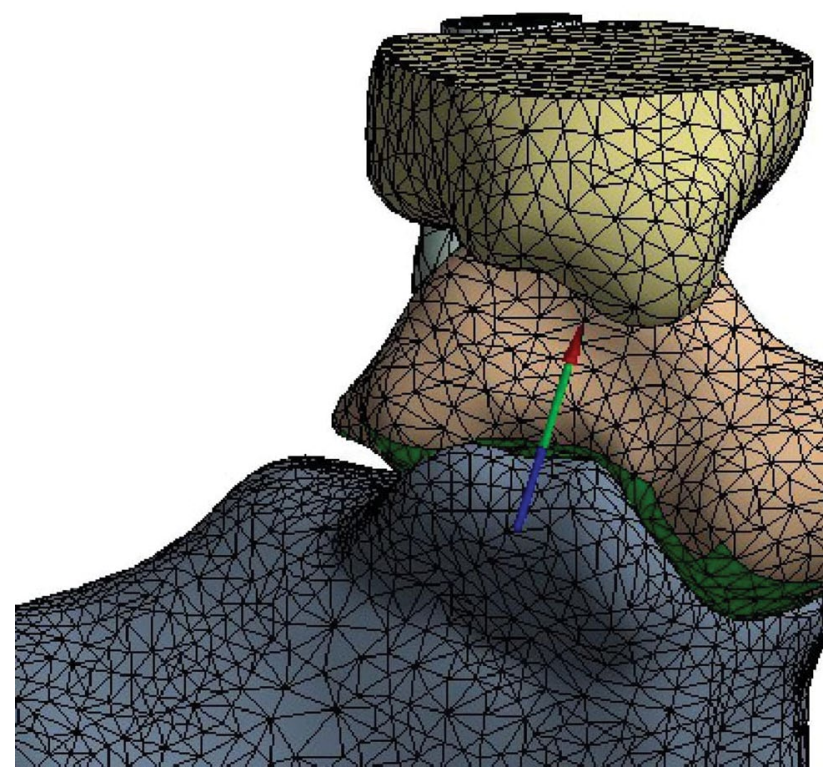

FIGURE 9. Direction of reaction force on the subtalar joint.

\begin{tabular}{|c|c|c|c|c|c|}
\hline \multicolumn{6}{|c|}{$\begin{array}{c}\text { TABLE IV } \\
\text { ANOVA analysis }\end{array}$} \\
\hline Subtalar joint pressure & Sum of squares & $\mathrm{df}$ & Mean square & $\mathrm{F}$ & $p$ \\
\hline Between groups & 1410,706 & 2 & 705,353 & 6.304 & 0.043 \\
\hline Within groups & 559,473 & 5 & 111,895 & & \\
\hline Total & 1970,179 & 7 & & & \\
\hline
\end{tabular}

\begin{tabular}{|llcc|}
\multicolumn{2}{c|}{$\begin{array}{c}\text { TABLE V } \\
\text { Correlation analysis }\end{array}$} & Böhler's angle & Pressure on the subtalar joint \\
\hline Böhler's angle & \multicolumn{1}{c|}{$\begin{array}{c}\text { Pearson's correlation } \\
\text { Pressure on the subtalar joint }\end{array}$} & $-0.832^{*}$ \\
& Sig. (2-tailed) & 0.010 \\
& Pearson's correlation & $-0.832^{*}$ & 1 \\
& Sig. (2-tailed) & 0.010 & \\
\hline
\end{tabular}

\section{DISCUSSION}

The integrity of calcaneal anatomical morphology is critical to ensure normal function of the hindfoot and stress conduction for weight bearing as well as to support the arch. ${ }^{[22,23]}$ Posterior facet incongruity has been confirmed to be an important predictor of poor clinical outcomes in calcaneal fractures. ${ }^{[24]}$ The articular incongruity of 1 to $2 \mathrm{~mm}$ step-offs has been shown to be associated with a considerable load shift in cadaver experiments. ${ }^{[5,6]}$ The most important concept that we have learned in recent years for the treatment of calcaneal fractures may be that the $3 \mathrm{D}$ calcaneal anatomy must be restored during treatment. ${ }^{[25]}$ Magnan et al. ${ }^{[26]}$ showed that a better reduction as measured by $\mathrm{CT}$ scanning might result in better outcomes. In this study, CT scan images were used with MIMICS $^{\circledR}$ software for FEA. The FEA studies have long been known as reliable complementary tools to quantitatively evaluate the 
biomechanical performance of tissues, organs, and articular joint. ${ }^{[27]}$ These studies mainly offer precise control of loading, motions, boundary conditions, and structural alterations in parametric studies of the joint response. In our study, change in the Böhler's angle and its effects on the pressure on the subtalar joint were evaluated, and the pressure on subtalar joint was found to decrease, as the Böhler's angle increased, and the pressure increased, when the Böhler's angle decreased.

To date, there are several radiographic parameters used for the description of the calcaneal fractures. The Böhler's angle is a well-established tool to quantify fracture displacement with a prognostic value in predicting morbidity associated with calcaneal fractures. ${ }^{[11]}$ It is a simple, rapid, and reliable measurement which offers several advantages in the clinical setting. ${ }^{[28]}$ In addition, it can be used to guide the fracture reduction during surgery. In clinical practice, one of the main surgical goals is to restore the Böhler's angle back to normal range of 25 to 40 degrees $^{[29]}$ to yield satisfactory results. ${ }^{[7,8]}$ However, there are several studies examining possible correlations between the restoration of the Böhler's angle and improved clinical outcomes. According to the literature, a Böhler's angle lower than 25 degrees increases the maximal calcaneal tension. ${ }^{[13]}$ A Böhler's angle of 0 increases the surgical subtalar arthrodesis by about 10 folds. ${ }^{[30]}$ When the angle is more than 40 degrees, the tension is slightly increased; however, it does not pose a problem in the joint. In the literature, two opposing views are available. In a review including 70 cases with displaced intra-articular calcaneal fractures, Paul et al ${ }^{[8]}$ reported that patients achieved good outcomes following operation, when the Böhler's angle was restored at $>10$ degrees. The outcomes of patients with a Böhler's angle of $\geq 10$ or $<10$ degrees who underwent surgery or conservative treatment and were followed were evaluated. In the patients without restored Böhler's angle, a higher pressure onto the subtalar joint was applied and unfavorable results were obtained, resulting in subtalar arthrodesis. However, Kundel et al. ${ }^{[3]}$ and Mauffrey et al. ${ }^{[31]}$ oppositely found no correlation between the Böhler's angle during follow-up and the final functional outcomes in the operative and conservative groups. In our study, we observed that Böhler's angle was an important parameter in calcaneus fractures, and we discussed the effects of change in the Böhler's angle on the subtalar joint. Unlike other studies, the pressure load on the subtalar joint was evaluated in this study.
Analysis of all models based in the reference model revealed that maximum tension values on calcaneus increased, while the Böhler's angle decreased, indicating a significant correlation. However, the increased Böhler's angle indicated increased the maximum tension values, indicating no statistical significance. The reaction force in the subtalar joint was also evaluated by comparing with the forces in the reference model. The increased Böhler's angle was found to be associated with a statistically significantly decreased amount of load on subtalar joint. However, the decreased Böhler's angle was correlated with the increased amount of load on subtalar joint, indicating statistical significance.

Nonetheless, there are some limitations to the present study. Muscular structures were not included in the analysis. Different muscle strengths may have caused different results. The reliability and validity of the study can be also increased with cadaveric studies and comparing the results with finite element models. Therefore, we recommended further studies to confirm these findings.

In conclusion, our study results suggest that decreased Böhler's angle increases the possibility of subtalar arthrosis and restoring this angle yield positive results. Overcorrection of the Böhler's angle seems not to increase the risk of subtalar arthrosis.

\section{Declaration of conflicting interests}

The authors declared no conflicts of interest with respect to the authorship and/or publication of this article.

\section{Funding}

The authors received no financial support for the research and/or authorship of this article.

\section{REFERENCES}

1. Clare MP, Sanders RW. Fractures and dislocations of the calcaneus. In: Bucholz RW, Heckman JD, Court-Brown C, Tornetta P, editors. Rockwood and Green's Fractures in Adults. 6th ed. Philadelphia: Lippincott Williams \& Wilkins; 2005. p. 2293-336.

2. Baca E, Koluman A. Modified percutaneous fixation for displaced intra-articular calcaneal fractures. Eklem Hastalik Cerrahisi 2019;30:168-74.

3. Kundel K, Funk E, Brutscher M, Bickel R. Calcaneal fractures: Operative versus nonoperative treatment. J Trauma 1996;41:839-45.

4. Kinner B, Schieder S, Müller F, Pannek A, Roll C. Calcaneocuboid joint involvement in calcaneal fractures. J Trauma 2010;68:1192-9.

5. Mulcahy DM, McCormack DM, Stephens MM. Intraarticular calcaneal fractures: Effect of open reduction and internal fixation on the contact characteristics of the subtalar joint. Foot Ankle Int 1998;19:842-8. 
6. Sangeorzan BJ, Ananthakrishnan D, Tencer AF. Contact characteristics of the subtalar joint after a simulated calcaneus fracture. J Orthop Trauma 1995;9:251-8.

7. Makki D, Alnajjar HM, Walkay S, Ramkumar U, Watson AJ, Allen PW. Osteosynthesis of displaced intra-articular fractures of the calcaneum: A long-term review of 47 cases. J Bone Joint Surg [Br] 2010;92:693-700.

8. Paul M, Peter R, Hoffmeyer P. Fractures of the calcaneum. A review of 70 patients. J Bone Joint Surg Br 2004;86:1142-5.

9. Böhler L. Diagnosis, pathology and treatment of fractures of the oscalcis. J Bone Joint Surg [Am] 1931;13:75-89.

10. Hyer CF, Atway S, Berlet GC, Lee TH. Early weight bearing of calcaneal fractures fixated with locked plates: A radiographic review. Foot Ankle Spec 2010;3:320-3.

11. Loucks C, Buckley R. Bohler's angle: Correlation with outcome in displaced intra-articular calcaneal fractures. J Orthop Trauma 1999;13:554-8.

12. Lee $\mathrm{D}$, Yoo JH, Son DW, Kim DH. Is the Bohler angle reliable for operative reduction of calcaneus fracture? J Orthop Sci 2019;24:521-5.

13. Isaacs JD, Baba $M$, Huang $P$, Symes $M$, Guzman M, Nandapalan $\mathrm{H}$, et al. The diagnostic accuracy of Böhler's angle in fractures of the calcaneus. J Emerg Med 2013;45:879-84.

14. Johnson JE, Lee P, McIff TE, Toby EB, Fischer KJ. Computationally efficient magnetic resonance imaging based surface contact modeling as a tool to evaluate joint injuries and outcomes of surgical interventions compared to finite element modeling. J Biomech Eng 2014;136:0410021-9.

15. Kocsis A, Váradi K, Szalai G, Kovács T, Bodzay T. Hybrid solution combining osteosynthesis and endoprosthesis for double column acetabular fractures in the elderly provide more stability with finite element model. Eklem Hastalik Cerrahisi 2019;30:106-11.

16. Konya MN, Aslan A, Bakbak S. How is hip prosthesis and proximal femoral nail stability affected by lesser trochanter fractures: A comparative finite element analysis. Eklem Hastalik Cerrahisi 2018;29:79-86.

17. Atmaca H, Özkan A, Mutlu I, Celik T, Ugur L, Kisioglu Y. The effect of proximal tibial corrective osteotomy on menisci, tibia and tarsal bones: A finite element model study of tibia vara. Int J Med Robot 2014;10:93-7.

18. Anderson AE, Ellis BJ, Maas SA, Peters CL, Weiss JA. Validation of finite element predictions of cartilage contact pressure in the human hip joint. J Biomech Eng 2008;130:051008.
19. Göçer H, Çirakli A, Uğur L, Yildiz A, Karadeniz S. Determination of the most appropriate surgical treatment in syndesmotic injury of ankle joint: Application of Taguchi method. Mechanika 2017;23:138-45.

20. Martens M, Van Audekercke R, Delport P, De Meester P, Mulier JC. The mechanical characteristics of cancellous bone at the upper femoral region. J Biomech 1983;16:971-83.

21. Ramlee MH, Sulong MA, Garcia-Nieto E, Penaranda DA, Felip AR, Kadir MRA. Biomechanical features of six design of the delta external fixator for treating Pilon fracture: A finite element study. Med Biol Eng Comput 2018;56:1925-38.

22. Epstein N, Chandran S, Chou L. Current concepts review: Intra-articular fractures of the calcaneus. Foot Ankle Int 2012;33:79-86.

23. Stagni R, Leardini A, O'Connor JJ, Giannini S. Role of passive structures in the mobility and stability of the human subtalar joint: A literature review. Foot Ankle Int 2003;24:402-9.

24. Janzen DL, Connell DG, Munk PL, Buckley RE, Meek RN, Schechter MT. Intraarticular fractures of the calcaneus: Value of CT findings in determining prognosis. AJR Am J Roentgenol 1992;158:1271-4.

25. Guerado E, Bertrand ML, Cano JR. Management of calcaneal fractures: What have we learnt over the years? Injury 2012;43:1640-50.

26. Magnan B, Samaila E, Regis D, Merlini M, Bartolozzi P. Association between CT imaging at follow-up and clinical outcomes in heel fractures. Musculoskelet Surg 2010;94:113-7.

27. Wilson W, van Donkelaar CC, van Rietbergen R, Huiskes $\mathrm{R}$. The role of computational models in the search for the mechanical behavior and damage mechanisms of articular cartilage. Med Eng Phys 2005;27:810-26.

28. Chen MY, Bohrer SP, Kelley TF. Boehler's angle: A reappraisal. Ann Emerg Med 1991;20:122-4.

29. Wang Q, Chen W, Su Y, Pan J, Zhang Q, Peng A, et al. Minimally invasive treatment of calcaneal fracture by percutaneous leverage, anatomical plate, and compression bolts--the clinical evaluation of cohort of 156 patients. J Trauma 2010;69:1515-22.

30. Csizy M, Buckley R, Tough S, Leighton R, Smith J, McCormack R, et al. Displaced intra-articular calcaneal fractures: Variables predicting late subtalar fusion. J Orthop Trauma 2003;17:106-12.

31. Mauffrey C, Klutts P, Seligson D. The use of circular fine wire frames for the treatment of displaced intra-articular calcaneal fractures. J Orthop Traumatol 2009;10:9-15. 